\title{
Capping Progress on Invasive Species?
}

The European Commission recently published its long-awaited draft legislation on invasive alien species (1). The proposed regulation implements a key target of the European Union Biodiversity Strategy (2), aiming to bring EU policy in line with the Convention on Biological Diversity targets for 2020, which obliges signatories to identify and prioritize invasive alien species and their pathways of invasion, to control or eradicate priority species, and to manage pathways to prevent the introduction and establishment of new invasive alien species (3).

An EU-wide regulation that coordinates a preventative and responsive system across the member states is a welcome step forward. However, one aspect of the draft risks fundamentally compromising its capacity to tackle the issue: The list of species to which the system would apply is strictly capped at a maximum of 50 species, for at least an initial period of 5 years after adoption (realistically, until 2020). This is only $3 \%$ of the 1500 invasive alien species already recognized as present and problematic in the European Union $(1,4)$, which generate a minimum estimated cost of $€ 12.5$ billion annually $(5,6)$.

The justifi cation for capping the number of priority species is "to provide member states with certainty regarding the extent and costs of the actions they will be expected to take." Given the recognized long-term cost effi ciencies of early action on invasive alien species (7), this economic justifi cation is a short-term one, placing the burden of action and a crushing fi nancial bill on future generations. The system should be fl exible, responsive, and able to be updated as frequently as needed. Unless the cap is altered, we risk missing a major opportunity, sacrificing longer-term ecological and economic benefi ts in the name of minimizing short-term input.

C. CARBONERAS, ${ }_{1}$ P. WALTON, 2 M. VILÀ ${ }_{3}$ * ${ }_{1}$ Royal Society for the Protection of Birds, The Lodge, Sandy, Bedfordshire, SG19 2DL, UK. 2Royal Society for the Protection of Birds, Edinburgh Park, Edinburgh, EH12 9DH, UK. 3Estación Biológica de Doñana (EBD-CSIC), E-41092, Sevilla, Spain 
244 fi nal, Brussels, 2011].

3. Convention on Biological Diversity, "Strategic Plan for

Biodiversity 2011-2020" (COP 10 Decision X/2, 2010).

4. M. Vilà et al., Front. Ecol. Environ. 8, 135 (2010).

5. C. Shine et al., "Assessment to support continued development

of the EU strategy to combat invasive alien species"

[Final Report for EC, Institute for European Environmental

Policy (IEEP), Brussels, 2010].

6. P. E. Hulme, P. Pyšek, W. Nentwig, M. Vilà, Science 324, 40

(2009)

7. R. P. Keller, D. M. Lodge, D. C. Finnoff, Proc. Natl. Acad.

Sci. U.S.A. 104, 203 (2007). 